\title{
AMELOBLASTOMATOUS CHANGE IN RADICULAR CYST OF THE JAW IN A NIGERIAN POPULATION
}

\author{
F.O. OMOREGIE, ${ }^{1}$ M. A SEDE ${ }^{2}$ AND, A. M OJO ${ }^{1}$ \\ ${ }^{1}$ Department of Oral Pathology/Oral Medicine and ${ }^{2}$ Department of Restorative Dentistry, University of Benin \\ Teaching Hospital, PMB 1111 , Benin, Edo 30000,1Nigeria
}

DOI: http://dx.doi.org/10.4314/gmj.v49i2.8

Corresponding Author:Dr. Osawe Felix Omoregie

E-mail: omoregiefo@yahoo.com

Conflict of Interest: None declared

\begin{abstract}
SUMMARY
Objective: To determine the incidence, age, gender, jaw-sites and subtypes of radicular cyst, and to determine the incidence of ameloblastomatous change in radicular cyst in a Nigerian population.

Method: A 10-year retrospective analysis of all diagnosed orofacial lesions in the Department of Oral Pathology and Medicine, University of Benin Teaching Hospital, Benin City, Nigeria.

Results: From the 785 diagnosed orofacial lesions within the study period; there were $54(6.9 \%)$ cases of radicular cysts of the jaws. The peak age group was the $3^{\text {rd }}$ decade $(n=23,42.6 \%)$ with a mean age of $31 \pm 1.7$ years. There were $29(53.7 \%)$ males and $25(46.3 \%)$ females, giving a ratio of 1.2:1. The mandible was the commonest jaw-site $(n=32,59.3 \%)$. There were 12 $(22.2 \%)$ cases of periapical cyst which were significantly associated with anterior maxillary site $(\mathrm{n}=8,14.8 \%)[\mathrm{p}=0.001]$. Seven $(13.0 \%)$ cases of cystic ameloblastoma were diagnosed among the radicular cysts, with a predilection of the lesions for $3^{\text {rd }}$ and $4^{\text {th }}$ decades of life $(n=6,11.1 \%)$, and posterior mandible $(\mathrm{n}=5,9.3 \%)$.

Conclusion: This study showed a low incidence of radicular cyst of the jaw among orofacial lesions and a relatively higher incidence of ameloblastomatous change in radicular cyst compared to previous reports. Immuno-histochemical examination is recommended to differentiate radicular cyst with ameloblastomatouslike change from cystic ameloblastoma arising from radicular cyst.
\end{abstract}

Keywords: Radicular cyst, Inflammation, Ameloblastomatous change, Immunohistochemistry, Jaw lesion

\section{INTRODUCTION}

The prevalence of periapical radicular cyst development varies from $7 \%$ to $54 \%$ of periapical radiolucencies. Whereas, under strict diagnostic criteria in which periapical pocket cyst (cyst with incomplete epithelial lining) is separated from periapical true cyst (complete epithelium lined bag-like structure), the prevalence is approximately $15 \% .{ }^{1}$ Most radicular cysts are found in the third to six decade of life, with predilection for males and the maxilla, especially the anterior maxilla, followed by the posterior maxilla, the posterior mandible and finally the anterior mandibular region. $^{2}$

Periapical cyst is the most common type of radicular cyst presumed to arise from the proliferation of epithelium at the root apex of non-vital tooth induced by keratinocyte growth factor produced due to inflammatory stimulus following pulp necrosis. The sources of the epithelium includes rest of Malassez (mostly), crevicular epithelium, sinus lining or lining of fistulous tracts. The other types of radicular cyst are lateral radicular cyst and residual radicular cyst.

The lateral radicular cyst is presumed to arise from rest of Malassez at the lateral aspect of the root portion of tooth due to inflammatory stimulus such as, periodontal disease or pulpal necrosis. Residual radicular cyst may arise from periapical inflammatory tissue that is not curetted at the time of tooth removal. Radicular cyst may exhibit reduction in size and spontaneous resolution from lack of inflammatory stimulus. ${ }^{1}$ It is also reported that periapical cyst up to $2 \mathrm{~cm}$ in diameter usually regress spontaneously after endodontic therapy to remove infected pulpal tissue or tooth extraction. ${ }^{3}$

Similarly, inflammatory mechanism has been implicated in the aetiology of ameloblastoma, particularly the unicystic type arising from neoplastic transformation of non-neoplastic epithelial lining of odontogenic cyst such as radicular cyst, dentigerous cyst and odontogenic keratocyst. ${ }^{4}$ However, a study involving patients mostly of Chinese ethnicity, reported that ameloblastomatous-like epithelial lining arising from chronic inflammation in radicular cyst and dentigerous cyst should be differentiated from true ameloblastomatous cystic lining arising from radicular 
cyst. $^{5}$ The study, therefore, recommended the application of additional criteria for diagnosis of unicystic ameloblastoma described by Robinson and Martine $z^{6}$ and Gardner $^{7}$ to differentiate unicystic ameloblastoma from ameloblastomatous-like lining in radicular cyst and dentigerous cyst.

This study aims to determine the incidence, age, gender, jaw sites and histological subtypes of radicular cyst, and to determine the incidence of ameloblastomatous change in radicular cyst in a Nigerian population.

\section{METHODS}

Ethical approval to carry out this study was obtained from the Hospital Ethical Committee. A 10-year (2001 to 2010) retrospective analysis of all diagnosed orofacial lesions was carried out in the Department of Oral Pathology and Medicine, University of Benin Teaching Hospital, Benin City, Nigeria. The clinical case notes, histopathology slides and reports of all diagnosed cases of radicular cyst among the orofacial lesions were selected and reviewed.

The variables analyzed include incidence of radicular cyst among diagnosed orofacial lesions, age, gender, jaw sites (mandibular anterior and posterior regions; maxillary anterior and posterior regions), radicular subtypes of the cysts and incidence of ameloblastomatous change in the cystic lining of the radicular cysts (subdivided into unicystic and multicystic types).

Bivariate analysis and statistical testing were used to estimate the strength of correlation of the variables analyzed (using Pearson's correlation). The confidence level was set at $95 \%$ and probability values (P-value) of $\mathrm{P}<0.05$ was regarded as significant.

\section{RESULTS}

Of the 785 diagnosed orofacial lesions within the study period, there were $54(6.9 \%)$ cases of radicular cysts of the jaws. The peak age group was the $3^{\text {rd }}$ decade $(n=23$, $42.6 \%)$ with a mean age of $31 \pm 1.7$ years. There were $29(53.7 \%)$ males and 25 (46.3\%) females, giving a ratio of 1.2:1. The mandible was the commonest jawsite $(n=32,59.3 \%)$, with $27(50.0 \%)$ of the cases occurring in the posterior mandibular region. There were $22(40.7 \%)$ maxillary lesions, with the lesions occurring equally in the anterior $(n=11,20.4 \%)$ and posterior $(n=11,20.4 \%)$ maxillary regions.

The unspecified radicular subtype for the cyst were those lesions that have enlarged to involve the periapical and lateral periodontal spaces.
There were $34(63.0 \%)$ unspecified subtype radicular cysts (Figure 1), occurring mostly in the $3^{\text {rd }}$ decade of life $(n=14,25.9 \%)$, with slight male predilection $(n=19$, $35.2 \%$ ) and a statistically significant association with the posterior mandibular region $(n=21,38.9 \%)$ $[\mathrm{p}=0.008]$.

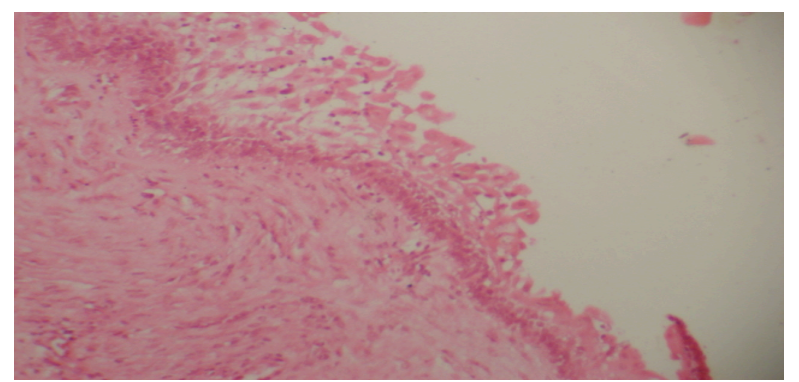

Figure 1 Radicular cyst lined by oedematous stratified squamous epithelium and an outer thick fibrous capsule (H\&E x 40).

Twelve (22.2\%) periapical cysts were diagnosed (Figure 2), with peak age in the $3^{\text {rd }}$ decade of life $(n=6$, $11.1 \%)$ and slight female predilection $(n=7,13.0 \%)$. There was statistically significant association of the periapical cysts with the anterior maxilla $(n=8,14.8 \%)$ $[\mathrm{p}=0.001]$. Only one $(1.8 \%)$ case of residual cyst was found, occurring in a male at the $5^{\text {th }}$ decade of life and in the posterior mandibular region.

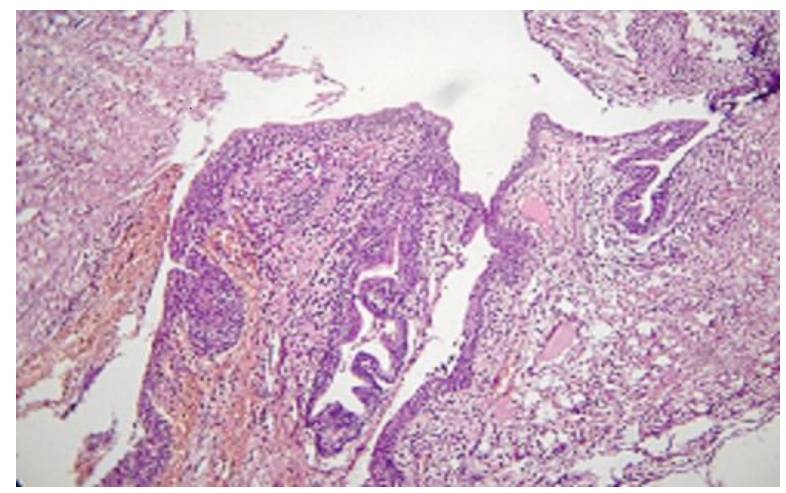

Figure 2 Periapical cyst with cystic cavity lined by stratified squamous epithelium and an outer granulation tissue with chronic inflammatory cell infiltration and a few blood vessels (H\&E x10)

Seven $(13.0 \%)$ cases of cystic ameloblastoma were diagnosed among the radicular cysts (Figure 3), with predilection of the lesions for the $3^{\text {rd }}$ and $4^{\text {th }}$ decades of life $(n=6,11.1 \%)$ and the posterior mandibular region $(\mathrm{n}=5,9.3 \%)$. The multicystic ameloblastoma $(\mathrm{n}=5$, $9.3 \%$ was the most common type of ameloblastomatous change observed, with predilection for the posterior mandibular region $(n=4,7.4 \%)$ and a statistically significant predilection of the lesion for females $(n=3,5.6 \%)[p=0.028]$. 
Table 1 Age distribution of radicular cysts of the jaws

\begin{tabular}{|c|c|c|c|c|c|c|c|}
\hline \multirow{2}{*}{$\begin{array}{l}\text { AGE GROUP } \\
\text { (Years) }\end{array}$} & \multicolumn{5}{|c|}{ RADICULAR CYST SUBTYPES } & \multirow[b]{2}{*}{ Total } & \multirow[b]{2}{*}{$\%$} \\
\hline & Unspecified & Periapical Cyst & Residual Cyst & $\begin{array}{c}\text { Ameloblasto } \\
\text { Unicystic }\end{array}$ & $\begin{array}{l}\text { matous change } \\
\text { Multicystic }\end{array}$ & & \\
\hline $0-10$ & 1 & --- & --- & -- & --- & 1 & 1.8 \\
\hline $11-20$ & 9 & 2 & --- & --- & --- & 11 & 20.4 \\
\hline $21-30$ & 14 & 6 & --- & 1 & 2 & 23 & 42.6 \\
\hline $31-40$ & 4 & 1 & --- & --- & 2 & 7 & 13.0 \\
\hline $41-50$ & 3 & 1 & 1 & -- & --- & 5 & 9.3 \\
\hline $51-60$ & 1 & 1 & --- & -- & --- & 2 & 3.7 \\
\hline $61-70$ & 1 & --- & --- & -- & --- & 1 & 1.8 \\
\hline$\geq 71$ & 1 & 1 & --- & 1 & 1 & 4 & 7.4 \\
\hline Total & 34 & 12 & 1 & 2 & 5 & 54 & 100 \\
\hline$\%$ & 63.0 & 22.2 & 1.8 & 3.7 & 9.3 & 100 & \\
\hline
\end{tabular}

Table 2 Gender distribution of radicular cysts of the jaws

\begin{tabular}{cccccccc}
\hline GENDER & \multicolumn{2}{c}{ RADICULAR CYST SUBTYPES } & & & \\
& Unspecified & Periapical Cyst & Residual Cyst & $\begin{array}{c}\text { Ameloblastomatous change } \\
\text { Unicystic }\end{array}$ & Multicystic & Total & $\%$ \\
\hline Male & 19 & 5 & 1 & 2 & 2 & 29 & 53.7 \\
Female & 15 & 7 & -- & -- & 3 & 25 & 46.3 \\
\hline Total & $\mathbf{3 4}$ & $\mathbf{1 2}$ & $\mathbf{1}$ & $\mathbf{2}$ & $\mathbf{5}$ & $\mathbf{5 4}$ & $\mathbf{1 0 0}$ \\
$\%$ & $\mathbf{6 3 . 0}$ & $\mathbf{2 2 . 2}$ & $\mathbf{1 . 8}$ & 3.7 & $\mathbf{9 . 3}$ & $\mathbf{1 0 0}$ & \\
\hline
\end{tabular}

Table 3 Jaw-site distribution of the radicular cysts

\begin{tabular}{|c|c|c|c|c|c|c|}
\hline \multirow{3}{*}{$\begin{array}{l}\text { RADICULAR CYST } \\
\text { SUBTYPE }\end{array}$} & \multicolumn{4}{|c|}{ JAW-SITES } & \multirow{3}{*}{ TOTAL } & \multirow{3}{*}{$\%$} \\
\hline & \multicolumn{2}{|c|}{ MANDIBLE } & \multicolumn{2}{|c|}{ MAXILLA } & & \\
\hline & Anterior & Posterior & Anterior & Posterior & & \\
\hline Unspecified & 4 & 21 & 2 & 7 & 34 & 63.0 \\
\hline Periapical cyst & -- & 1 & 8 & 3 & 12 & 22.2 \\
\hline Residual cyst & -- & 1 & -- & -- & 1 & 1.8 \\
\hline \multicolumn{7}{|c|}{ Ameloblastomatous change } \\
\hline Unicystic & 1 & -- & -- & 1 & 2 & 3.7 \\
\hline Multicystic & -- & 4 & 1 & -- & 5 & 9.3 \\
\hline \multirow[t]{2}{*}{ TOTAL } & 5 & 27 & 11 & 11 & 54 & 100 \\
\hline & \multicolumn{2}{|c|}{32} & \multicolumn{2}{|c|}{22} & & \\
\hline$\%$ & \multicolumn{2}{|c|}{59.3} & \multicolumn{2}{|c|}{40.7} & 100 & \\
\hline
\end{tabular}




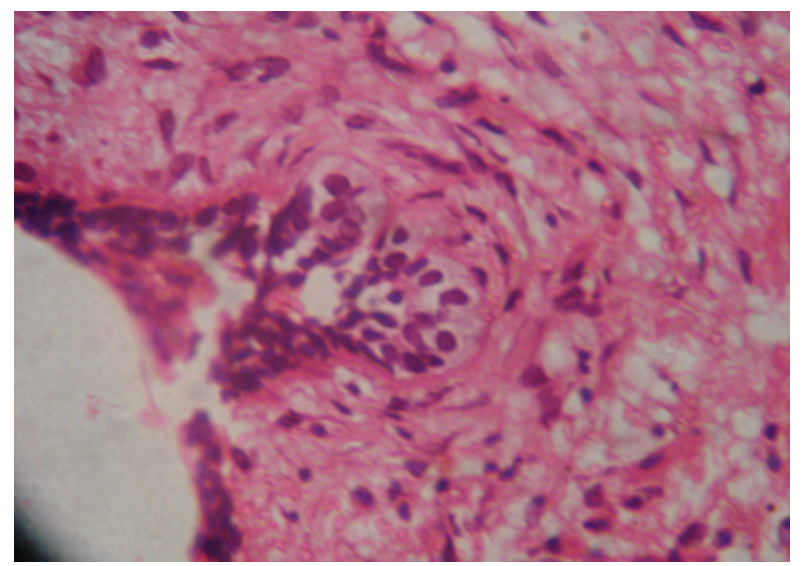

Figure 3 Unicystic ameloblastoma arising in radicular cyst, with a focal transformation of stratified squamous epithelium to ameloblastomatous epithelium, consisting of loosely attached cells resembling stellate reticulum, palisaded cuboidal basal cells with reverse polarity and hyperchromatic nucleus and pale cytoplasm. There was chronic inflammatory cell infiltration of the outer fibrous capsules.

\section{DISCUSSION}

The speculation of inflammatory aetiology for ameloblastoma remains controversial. There is difficulty in differentiating ameloblastomatous-like change in inflamed cystic linings of radicular cyst and dentigerous cyst from a true unicystic ameloblastoma. ${ }^{5}$ However, there are reports of ameloblastoma arising from cystic linings of radicular cyst, ${ }^{4,5}$ which suggests inflammatory origin for the lesion. Similarly, in this study, ameloblastomatous change $(13.0 \%)$ was found in the cystic lining of some of the radicular cysts reviewed. Although, there was a low incidence of radicular cyst $(6.9 \%)$ among the diagnosed orofacial lesions in this Centre, a relatively higher incidence of ameloblastoma arising from radicular cyst was observed in the Nigerian population studied compared to previous report. ${ }^{8}$ Therefore, this study also supports a possible inflammatory aetiology for ameloblastoma.

Most of the radicular cysts were observed in patients in the $3^{\text {rd }}$ decade of life, with almost equal gender distribution and a predilection for the posterior mandible, especially amongst the unspecified radicular cyst subtype. The site and gender predilection for radicular cyst in this study are in contrast with previous reports. ${ }^{2,8}$ The preponderance of the unspecified radicular cyst subtype in males and the posterior mandibular region could be due to a higher incidence of carious tooth in the region; and the reluctance of most males to present for treatment until the cyst has grown to very large size causing facial disfigurement.
The periapical cysts studied were mostly found in the anterior maxilla, which is the jaw-site often at risk of traumatic injuries to the tooth and dental caries. Similarly, previous report in this centre has linked carious incisor tooth with the development of periapical cyst. ${ }^{9}$

The cystic ameloblastomas developed from the lining of radicular cysts in this study were mostly in the posterior mandibular region, with predilection of the multicystic type for females. Similarly, cases of ameloblastoma arising in radicular cystic lining in females have been documented. ${ }^{10,11}$ This suggests that hormonal factors may play a role in neoplastic transformation of the cystic lining of radicular cysts.

A comparison of the histological features of the cystic lining of radicular cyst with those of the cyst with ameloblastomatous change showed, a focal transformation of stratified squamous epithelium to ameloblastomatous epithelium, with loosely attached cells resembling stellate reticulum, palisaded cuboidal basal cells showing reverse polarity of the nucleus, hyperchromatic nucleus and pale cytoplasm. There was chronic inflammatory cell infiltration of the outer fibrous capsule. These features of ameloblastomatous change in radicular cyst lining are similar to those previously reported. ${ }^{11}$

Sometimes, it may be difficult to histologically differentiate radicular cyst with inflamed cystic lining, showing ameloblastomatous-like change, from true cystic ameloblastoma arising from radicular cyst. ${ }^{5}$ Recent immuno-histochemical studies on the level of proliferating cell nuclear antigen (PCNA), the expression of p53 protein and MDM2 protein has shown that they could be helpful in differentiating radicular cyst from a true cystic ameloblastoma. Radicular cyst has a lower level of PCNA compared to cystic ameloblastoma and there is a corresponding higher aggressive biological behaviour of cystic ameloblastoma compared to radicular cyst. ${ }^{12}$

In addition, ameloblastoma has a higher level of MDM2 protein than radicular cyst, but no positive expression of $\mathrm{p} 53$ protein was found in the ameloblastoma and radicular cyst studied. ${ }^{13}$ However, a more recent study detected a positive expression of p53 protein in $8.3 \%$ of the radicular cyst studied. ${ }^{14}$ Therefore, we recommend that immuno-histochemical examination of formalin fixed, paraffin wax embedded specimens of histologically diagnosed radicular cyst with ameloblastomatous-like change and ameloblastoma arising in radicular cyst should be performed to determine the level of PCNA, positive expression of $\mathrm{p} 53$ protein and MDM2 protein, which 
could be helpful to confirm the diagnosis of these lesions.

In conclusion, this study showed a low incidence of radicular cyst of the jaw among orofacial lesions and a relatively higher incidence of ameloblastoma arising in radicular cyst compared to previous reports. This study also supports a possible inflammatory aetiology for ameloblastoma. We recommend immunohistochemical examination to determine the level of PCNA, p53 protein and MDM2 protein, in radicular cyst with ameloblastomatous-like change and cystic ameloblastoma arising from radicular cyst to confirm the diagnosis of these lesions.

\section{REFERENCES}

1. Neville BW, Damm, DD, Allen CM, Bouquot JE. Periapical cyst (Radicular cyst; apical periodontal cyst). Oral and Maxillofacial Pathology, $3^{\text {rd }}$ Edition published by Saunders Elsevier, St Louis, Missouri, 2009:pp130-135.

2. Regezi JA, Scuibba J. Radicular (periapical) cyst. Oral Pathology: clinicopathologic correlations, $2^{\text {nd }}$ Edition published by WB Saunders Company, Philadelphia, 1989: pp322-327.

3. Cawson RA, Binnie WH, Eveson JW. Periodontal radicular cysts. Colour Alas of Oral Disease: a clinicopathologic correlations. $2^{\text {nd }}$ Edition published by Wolfe Mosby, England, 1994: pp5.9 - 5.13.

4. Holmlund A, Anneroth G, Lundquist G, Nordenram A. Ameloblastoma originating from odontogenic cyst. J Oral Pathol Med 1991;20 (7): 318-321.

5. Sudiono J, Zain RB. A Comparative Histopathological Study of Epithelial Linings of Odontogenic Cysts and Unicystic Ameloblastomas, Annals Dent Univ Malaya $1998 ; 5: 29-34$
6. Robinson $\mathrm{L}$ and Martinez MG. Unicystic ameloblastoma. A prognostically distinct entity. Cancer 1977;40:278-285.

7. Gardner DG. Some current concepts on the pathology of ameloblastomas. Oral Surg Oral Med Oral Path 1996; 82: 660-669.

8. Rajendran R, Sivapathasundharam B. Cyst and tumours of odontogenic origin: ameloblastoma. Shafer's textbook of oral pathology, $5^{\text {th }}$ edition published by Elsevier New Delhi, India 2006: 381-391.

9. Omoregie FO, Saheeb BDO, Odukoya O, Ojo MA. A Clinicopathologic Correlation in the Diagnosis of Periradicular Lesions of Extracted Teeth. J Oral Maxillofac Surg 2009;67:13871391.

10. Siar $\mathrm{CH}$, Nakano K, Chelvanayagam PI, Ng KH et al. An unsuspected ameloblastoma in the subpontic region of the mandible with consideration of pathogenesis from the radiographic course. Eur J Med Res 2010; 15(3):135-138.

11. Meetkamal and Kaur P. An unusual case of unicystic ameloblastoma involving the anterior of Maxilla. J Clinical Diag Research 2010; 4: 3659-3663.

12. Piattelli A, Fioroni M, Santinelli A, Rubini C. Expression of proliferating cell nuclear antigen in ameloblastomas and odontogenic cysts. Oral Oncology 1998; 34 (5): 408-412.

13. Carvalhais J, Aguiar M, Araújo V, Araújo N et al. p53 and MDM2 expression in odontogenic cysts and tumours. Oral Dis 1999; 5(3): 218-222.

14. Piattelli A, Fioroni M, Santinelli A, Rubini C. P53 protein expression in odontogenic cysts. $J$ Endod 2001;27 (7): 459-461 